\title{
Adhesion G Protein-Coupled Receptor E1
}

National Cancer Institute

\section{Source}

National Cancer Institute. Adhesion G Protein-Coupled Receptor E1. NCI Thesaurus.

Code C126952.

Adhesion G protein-coupled receptor E1 ( $886 \mathrm{aa}, \sim 98 \mathrm{kDa}$ ) is encoded by the human ADGRE1 gene. This protein is involved in cell adhesion, signaling and immunity. 